\title{
APLICABLE HORIZONTAL WIND TURBIN MODEL FAMILY SCALE
}

\author{
Nitabian Iftita Rahayu ${ }^{1}$, Muhamad Abdul Jumali ${ }^{2}$ \\ Industrial Engineering Department, Faculty of Industrial Technology ${ }^{1,2}$ \\ University of PGRI AdiBuana Surabaya \\ email : nitabian_cute@yahoo.co.id
}

\begin{abstract}
The aplicabel of horizontal wind turbine. There is two alternative two develop wind turbine design that generator or blade, in order to develop horizontal wind turbine This reesearch select the partdesign to develop generator. The angle design betwen coil and magnetic field must to optimal degree. There are seven angle from 60 degree to 120 degee which angle test. There is range of the optimal degree from 80 degree to 100 degree to develop wihd turbine.
\end{abstract}

Keywords: optimal degree, develop generator, angle test.

\section{INTRODUCTION}

In the era renewable energy to be, the one is wind energy sources have improvement interest due both to the technological of wind turbines and to be increase of wind power maximum efficiency. At present the wind turbines energy in order to keep the optimum energy. We will concepted to wind turbine is a set of tools that working with energy changeable from wind energy to mechanical and pass through to the electrical energy. All of processing get any losses from one energy to another. Include from wind energy is determined by speed of wind, specific mass of the air and the area of wind, and usually higher that blades remove. Cam and Yildiz (2006), Show that the ANFIS method get the optimal energy. Boukhezzar (2009), has method to the optimum energy for adjust blades pitch controller. Ying, Shiue, and Ching (2009), get
MPPT for PM wind generator using gradient approximation . Steinbuch et al (1988), get Optimal Control Of Wind Power Plants Dadone and Dambrosio (2003), get Estimator based adaptive fuzzy logic control technique for a wind turbine-generator system, Ansari and Velusami (2010), get DMLHFLC (Dual mode linguistic hedge fuzzy logic controller) for an isolated wind diesel hybrid power system with BES (battery energy storage) unit Generator Wind turbine has two main device that the generator and blade. The blade which capture the wind speed and convert to kinetic energy to rotate the generator, and the generator is the device to convert kinetic energy rotation come to low ectrical energy. The aplicable horizontal wind turbine model this experiment on generator optimal singel betwen coil and the magnetic field.

\section{OBJECT}

We foccuse on the develop the horizontal wind turbine model, especially on optimalization of angle betwen megnetic field and coil. In Faraday law that electromagnetic force occur from differensial of magnetic flux on the coil based on time domain. In order to optimalization the electromagnetic force, we must control position betwen the coil and the flux magnetic field. the angle of normally magnetic field is showed. In this research, it has been made the device, Lets see the figure 1 , it is the device on this figure has a scale and magnetic that adjust from 50 degree until 130 degree. 


\section{Tibuana}

Journal of applied Industrial Engineering-University of PGRI Adi Buana

p-ISSN 2622-2027

$e$-ISSN 2622-2035

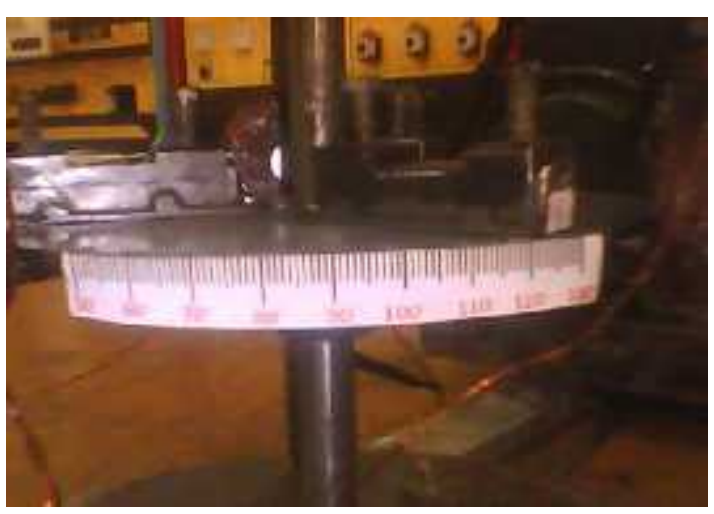

Figure 1. Scale of Angle

The rotary of motor that can be made voltage of electric. With variable angle can be adjusted for each rotary.

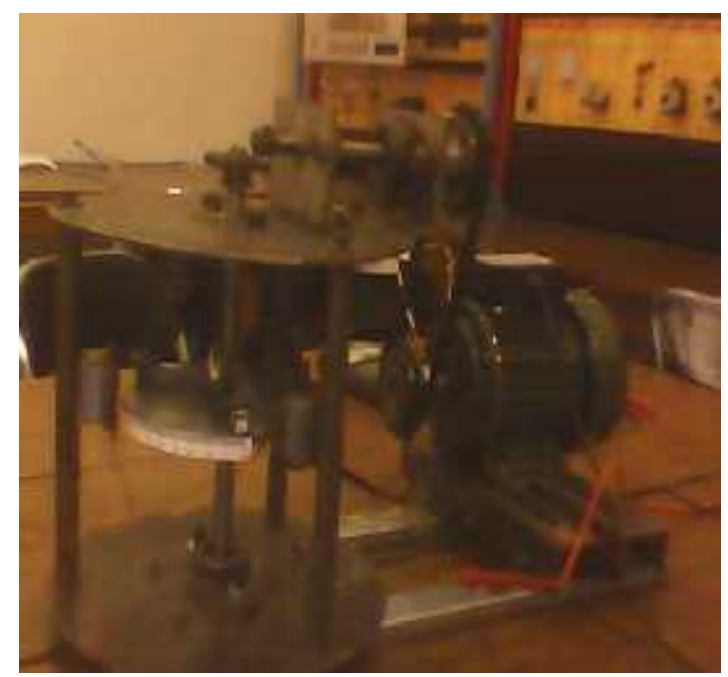

Figure 2. The Generator

Figure 2 , angle the generator has two device that coil and magnetic field. The constant rotary is made from motor. The optimal must find from constant rotary.

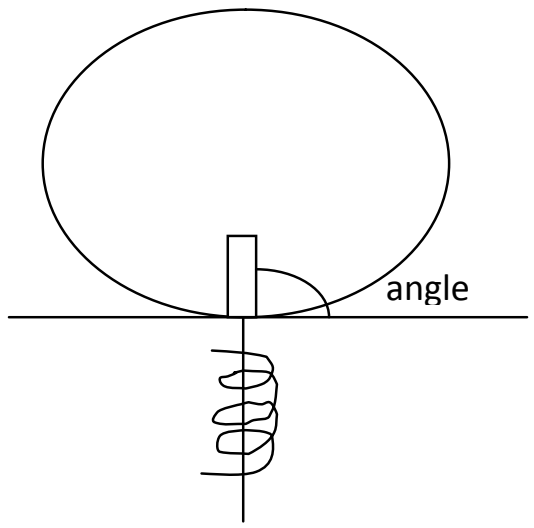

Figure 3. The configuration of angle betwen magnetic field and coil 


\section{Tibuana}

Journal of applied Industrial Engineering-University of PGRI Adi Buana

p-ISSN 2622-2027

$e$-ISSN 2622-2035

Figure 3 explain the angle that adjust form coil and magnetic field.

\section{METHODOLOGY}

The instalation of generator follow two main device of coil and the magnet. We have 7 angle betwen coil and magnetic field -100, -200, $300,00,100,200,300$. We can test which the angle can give the best energy. The constant rotary from mator will produce the voltage that we measure. Wind Turbine modeling must been given to the experiment.

Modeling :

The first we get a wind turbine power that can be expressed by equation (1) below:

$$
\mathrm{P}=0.5 \rho \mathrm{U}^{3}
$$

Where $\mathrm{P}$ is power of wind, the specific mass of air is $\rho$ and $U$ is wind speed and power of wind converts into torque with expression on equation (2);

$$
\mathrm{P}=\mathrm{k} \tau \omega
$$

Where $\mathrm{k}$ is change constants, $\tau$ is torque and $\omega$ is rotary speed. Next, the power of turbine to be changed to electric power with expression equation (3);

$$
\mathrm{P}_{\mathrm{e}}=\mathrm{V} \mathrm{I}
$$

Where Pe is electric Power, V is electric, voltage and $\mathrm{I}$ is electric current. On the experiment we will look at a model and experiment.

\section{EXPERIMENT}

The main goal of this experiment wants to show that the optimal angel betwen coil and magnetic field at the constant rotation. Figure 4 , show the eksperiment of angle adjustment. The result of the eksperiment is shown in table 1. The experiment has been done in teen each angle. One of the result is shown in table 1. Each rotary is been measued of electric voltage.

Table 1. Result of Experiment

\begin{tabular}{lll}
\hline No & Angle & Voltage \\
\hline 1. & $50^{\circ}$ & $0.1 \mathrm{v}$ \\
2, & $60^{\circ}$ & $0.1 \mathrm{v}$ \\
3. & $70^{\circ}$ & $0.2 \mathrm{v}$ \\
4. & $80^{\circ}$ & $0.3 \mathrm{v}$ \\
5. & $90^{\circ}$ & $0.3 \mathrm{v}$ \\
6. & $100^{\circ}$ & $0.3 \mathrm{v}$ \\
7. & $110^{\circ}$ & $0.2 \mathrm{v}$ \\
8. & $120^{\circ}$ & $0.1 \mathrm{v}$ \\
9. & $130^{\circ}$ & $0.1 \mathrm{v}$ \\
\hline
\end{tabular}




\section{Tibuana}

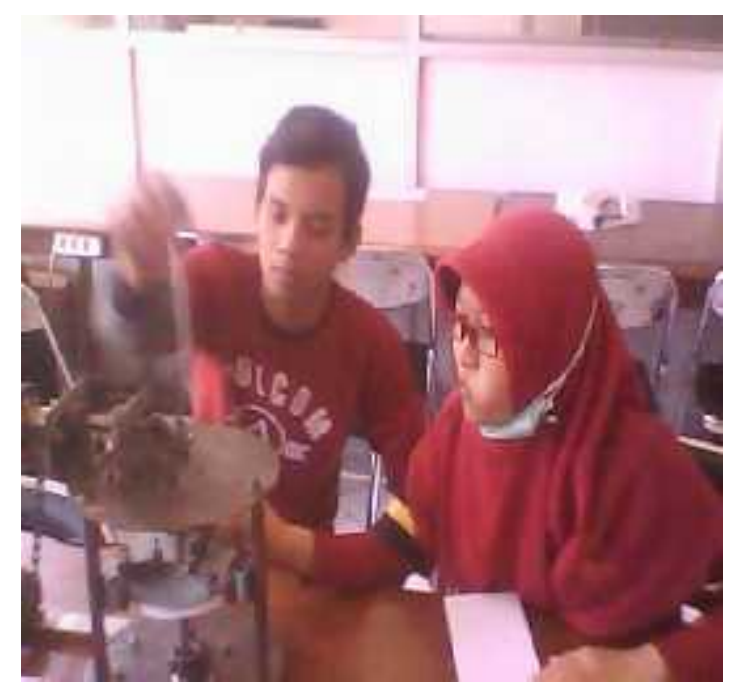

Figure 4. Test of Angle Optimization

\section{RESULT AND DISCUSSION}

On the scale of $50^{\circ}$ we get the voltage 0.1 Volt. See on figure 1 . And then, $n$ the scale of $60^{\circ}$ we get the voltage 0.1 Volt. And so on the scale of $70^{\circ}$ we get the voltage 0.2 Volt. Rising value on the scale of $80^{\circ}$ we get the voltage 0.3 Volt. And on the scale of $90^{\circ}$ we get the voltage 0.3 Volt. Also on the scale of $100^{\circ}$ we get the voltage 0.3 Volt. Slow down occur at the scale of $110^{\circ}$ we get the voltage 0.2 Volt. Also $\mathrm{n}$ the scale of $120^{\circ}$ we get the voltage 0.1 Volt. The last on the scale of $130^{\circ}$ we get the voltage 0.1 Volt.

From the experiment, we get the result that the optimal power occur at the angle of 80 until 100 degree that show on the table 1 the voltage is 0.3 volt. The other angle is below of 0.3 volt that 0.2 and 0.1 volt.

\section{CONCLUSION}

From result and discussion, it can be made conclusion that the system better on 80 until 100 degree.

\section{REFERENCES}

1. Alata, M., Al-Nimr, M. A., \& Qaroush, Y., 2005, Developing a multipurpose sun tracking system using fuzzy control, Energy Conversion and Management, no.46, p.1229-1245.

2. B. Boukhezzar, L. Lupu, H. Siguerdidjane, M. Hand, 2007, Multivariable control strategy for variable speed, variable pitch wind turbines, Renewable Energy no.32, p.1273-1287

3. B. Boukhezzar, H. Siguerdidjane, 2009, Nonlinear control with wind estimation of a
DFIG variable speed wind turbine for power capture optimization, Energy Conversion and Management no.50, p.885892

4. Calderaro, V., Galdi, A. Piccolo, P., Siano, 2008, A fuzzy controller for maximum energy extraction from variable speed wind power generation systems, Electric Power Systems Research no.78, p.1109-1118.

5. Cam, E., \& Yildiz, O, 2006, Prediction of wind speed and power in the central Anatolian region of urkey by adaptive neuro-fuzzy inference systems (ANFIS).

6. Dadone,A., Lorenzo Dambrosio, L., 2003, Estimator based adaptive fuzzy logic control technique for a wind turbinegenerator system, Energy Conversion and Management no.44, p.135-153.

7. M. Mohamed Thameem Ansari, S. Velusami, 2010, DMLHFLC (Dual mode linguistic hedge fuzzy logic controller) for an isolated wind diesel hybrid power system with BES (battery energy storage) unit, Energy no.35, p.3827-3837.

8. M. Steinbuch, W.W. De Boer, O.H. Bosora, S.A.W.M. Peter, J. Ploeg, 1988, Optimal Control Of Wind Power Plants, Journal of Wind Engineering and Industrial Aerodynamics, no.27, p.237-246.

9. R. Ata , Y. Kocyigit, 2010, An adaptive neuro-fuzzy inference system approach for prediction of tip speed ratio in wind turbines, Expert Systems with Applications no.37, p.5454-5460. 


\section{Tibuana}

Journal of applied Industrial Engineering-University of PGRI Adi Buana

$p$-ISSN 2622-2027

$e$-ISSN 2622-2035

10. Ying-Yi Hong, Shiue-Der Lu, ChingSheng Chiou, 2009, MPPT for PM wind generator using gradient approximation,

Energy Conversion and Management no.50, p.82-89.

14 | TiBuana, Vol. 2, No. 1, 2019 